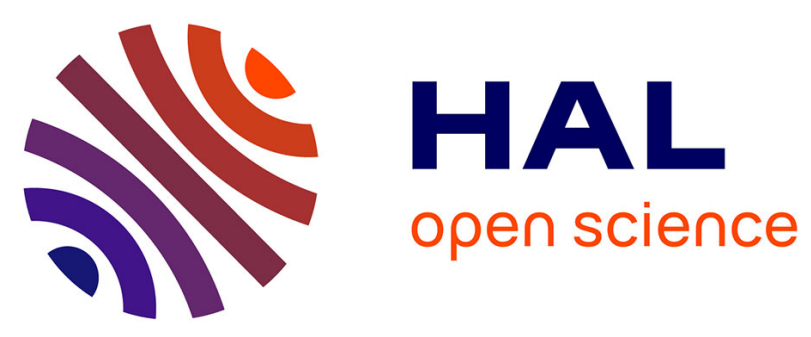

\title{
Risk management in transfusion after the HIV blood contamination crisis in France: the impact of the precautionary principle.
}

Eric Hergon, Grégoire Moutel, Nathalie Duchange, Lucile Bellier, Philippe Rouger, Christian Hervé

\section{To cite this version:}

Eric Hergon, Grégoire Moutel, Nathalie Duchange, Lucile Bellier, Philippe Rouger, et al.. Risk management in transfusion after the HIV blood contamination crisis in France: the impact of the precautionary principle.. Transfus Med Rev, 2005, 19 (4), pp.273-80. 10.1016/j.tmrv.2005.04.004 . inserm-00080244

\section{HAL Id: inserm-00080244 https://www.hal.inserm.fr/inserm-00080244}

Submitted on 15 Jun 2006

HAL is a multi-disciplinary open access archive for the deposit and dissemination of scientific research documents, whether they are published or not. The documents may come from teaching and research institutions in France or abroad, or from public or private research centers.
L'archive ouverte pluridisciplinaire HAL, est destinée au dépôt et à la diffusion de documents scientifiques de niveau recherche, publiés ou non, émanant des établissements d'enseignement et de recherche français ou étrangers, des laboratoires publics ou privés. 
RISK MANAGEMENT IN TRANSFUSION FOLLOWING THE HIV BLOOD

CONTAMINATION CRISIS IN FRANCE: THE IMPACT OF THE

PRECAUTIONARY PRINCIPLE

Eric Hergon ${ }^{1-2}$, Grégoire Moutel ${ }^{2}{ }^{,}$, Nathalie Duchange $^{2}$, Lucile Bellier ${ }^{2}$, Philippe Rouger ${ }^{1}$, Christian Hervé ${ }^{2}$

${ }^{1}$ Institut National de la Transfusion Sanguine, 6 rue Alexandre Cabanel, 75015 Paris, France

${ }^{2}$ Laboratoire d'Ethique médicale, de Droit de la santé et de Santé publique \& Institut International de Recherche en Ethique Biomédicale (IIREB), Faculté de médecine Necker, 156 rue de Vaugirard, 75015 Paris, France.

Short title: The precautionary principle in Transfusion Medicine

Correspondance to: Dr Eric Hergon, Institut National de la Transfusion Sanguine, 6 rue Alexandre Cabanel, 75015 Paris, France. Tel: 00331444930 21. Fax: 0033143060483. E-mail address: ehergon@ints.fr 


\begin{abstract}
Background: The importance of the precautionary principle in the field of public health was highlighted in France following the HIV contamination of blood products used for transfusion. However, the definition of this principle, its objectives, the way in which it should be applied, and its consequences had not been considered previously. The question as to whether the application of the precautionary principle is appropriate remains unanswered.
\end{abstract}

Objective: The aim of this study was to analyse the interpretations of the application of the precautionary principle in order to determine its consequences in terms of risk management and patient rights. This was accomplished by interviewing persons involved in Transfusion Medicine

Design: We conducted thirty-three interviews and describe the issues enunciated for and against the application of the precautionary principle.

Results: The precautionary principle concept was confusing to the respondents. A major issue emerging from the interviews was that the precautionary principle was perceived more as a means of protecting the decision-maker than as a means of protecting the patient.

Conclusions: Taken to its extreme, the use of the precautionary principle could prejudice sound medical decision-making. However, it was felt that it also can lead to the introduction of measures that update and gradually reduce risks associated with transfusion.

The precautionary principle was developed as part of European environmental policy. Its pertinence to public health became accepted in France following the HIV contaminated blood affair. In 1992, the precautionary principle was included in a proposed reform of the law concerning blood transfusion presented to the French parliament (1). The precautionary 
principle was thus considered by the public authorities in 1993 assuming that, for situations of scientific uncertainty, the possibility of risk should be taken into account in the absence of proof to the contrary. In 1994, the precautionary principle became one of the cardinal principles of health safety (3). Its definition was clarified in 1998 (4). The precautionary principle places a heavy obligation on those deciding policy; indeed, even in the absence of scientific certainty, the precautionary principle asserts that measures need to be taken to face potential serious risks.

In France, measures concerning the reduction of proven and potential infectious risks in transfusion (HIV, HCV, HBV, HTLV and vCJD) are proposed to the Minister for Health by the Agency for the Safety of Medical Products which must integrate precaution amongst its principles. While the French government developed a policy of high-quality hemovigilance, which contributes to the improvement of medical safety on objective and validated arguments, the precautionary principle was imposed in the field of public health when it was applied to blood transfusion. It was introduced with a view to anticipating the consequences of the potential risk of transfusion-transmission of prion disease (ie vCJD).

In this study we examined the interpretations of 33 individuals, involved in Transfusion Medicine in France, of the precautionary principle and analysed them on the basis of four aspects: historical basis, social significance, means of application and consequences. The aim of the study was to determine current attitudes towards the usefulness of the precautionary principle and its appropriate application by exploring the following questions: Does the precautionary principle provide useful elements for the management of risks associated with blood transfusion? Is the precautionary principle appropriate to apply to the risk management decision-making processes?

We felt that an analysis of the perceptions that these individuals have of the precautionary principle should make it possible to evaluate its relevance as well as to identify ways to 
improve the procedures for managing risks associated with blood transfusion. It was felt also that the information obtained would also be of value to those working in other fields of public health.

\section{MATERIALS AND METHODS}

This study examined the perceptions of those involved in Transfusion Medicine about the precautionary principle in general and how it applied to the blood transfusion in particular. This work is the result of a three years research project supported by both the National Institute of Blood Transfusion (INTS) and the International Institute of Research in Ethics and Biomedicine (IIREB).

\section{Interviewees:}

The study was carried out by means of interviews (5). The questions asked related to two major themes: the precautionary principle in general; and its application to blood transfusion. Among parties involved in blood transfusion, thirty-three individuals agreed to be interviewed: hospital doctors $(n=7)$, doctors at blood transfusion centers $(n=10)$, public health decision-makers $(n=8)$, politicians $(n=3)$, the President of the French Haemophilia Association, the President of the French Federation of Blood Donors, a hospital director, a representative from the National Agency of Health Accreditation and Evaluation; and the President of the French National Ethics Consultative Committee.

\section{Data Elaboration:}

The interviews were carefully recorded. For their analysis, a grid was elaborated and validated by experts belonging to the last two cited institutions with the aim of isolating those elements relating to the historical basis, the social significance, the methods of application, and the consequences of the precautionary principle. The grid was structured according to the 
two major themes and subdivided into different topics: the precautionary principle in general (origin, definition and signification, objective of its application); and the precautionary principle in the context of blood transfusion (significance, role in the management of risks in transfusion- scientific evaluation- decision taking - acceptability of measures taken, information, consequences in term of responsibility). In the first instance, a synthesis of each interview was made by extracting the different issues raised and classifying them in the grid. In the second instance, the number of occurrence of each issue was counted.

\section{Expression of Results:}

The results take into account first, the most frequently cited elements and second, less frequently reported information that specifically highlighted a particular subject, considering the level of expertise of the interviewee. The results were then presented to a group of experts made up of INTS and IIREB members. Because of the number and the method of choosing the interviewees, the results obtained do not necessarily represent an exhaustive or precise view of the question; rather, the results represent a first approach for dealing with the perception of the precautionary principle. 


\section{RESULTS}

\section{The precautionary principle in general}

Interpretations of the precautionary principle by the interviewees were based on three dominant elements: the founding event, doubts concerning the capacity to manage complex systems, and the vision of the precautionary principle. It was interesting to note a great diversity of knowledge about the precautionary principle, that emerged from the answers of the interviewees.

Founding event: Knowledge of the precautionary principle was generally associated with the HIV contaminated blood affair $(\mathrm{n}=29)$. Most felt that this was the founding event in the implementation of the precautionary principle in the field of health. Some $(n=7)$ cited the speech of the Minister of Health and Humanitarian Action during the presentation of the proposed law reform concerning blood transfusion to the French parliament in November 1992 (1). This speech had introduced the notion of the precautionary principle in the field of blood transfusion. The interviewees who cited this speech were notably involved in the manufacture of blood products or members of public institutions. Others $(n=9)$ stressed the importance of the emergence of variant Creutzfeldt-Jakob disease (vCJD) in strengthening the use of the precautionary principle.

Doubts concerning the capacity to manage complex systems: The interviewees expressed a lack of confidence in the capacity of decision-makers to manage large administrative and production systems $(n=21)$. This lack of confidence was due to several health disasters (contaminated blood, growth hormone and bovine spongiform encephalopathy). They felt that the social significance of the precautionary principle was high because of major demands 
on behalf of the interviewees of the following: safety in the face of what is seen as a failure of prevention $(\mathrm{n}=6)$; participation in the decision-making process from all parties concerned ( $\mathrm{n}$ $=12$ ); identification of those responsible for decision-making $(\mathrm{n}=16)$; and the potential risks to be considered before action, without waiting for confirmation of the results of scientific research $(n=10)$.

The vision of the precautionary principle: The majority of the interviewees saw the precautionary principle as a principle based on the need for political action, the nature and legal consequences of which are unclear $(n=30)$. Many feared being held responsible ( $n$ $=20$ ). According to some $(n=6)$ (doctors from blood transfusion centers and public health decision-makers), the precautionary principle was seen as part of the risk management strategy in a public health setting. However, a small number of respondents were able to give a clear definition of the principle $(\mathrm{n}=13)$. For some, the aim of the precautionary principle was a way to protect the decision-maker and to reduce the potential risk associated with scientific uncertainty $(\mathrm{n}=15)$. Finally, there was some confusion, concerning transmittable disease prevention, between potential risks of unknown probability and risks of low but measurable probability $(\mathrm{n}=5)$.

\section{The precautionary principle applied to blood transfusion}

When applied to blood transfusion, the respondents indicated that the interpretations of the precautionary principle were built around three aspects: that it is a response to society's distrust; that it is a method for managing the potential risk of prion (vCJD) contamination by blood transfusions;-; and that it supports a demand for risk zero. 
A response to society's distrust of blood transfusion: The interviewees asserted that society had lost confidence not only in blood transfusion, but also in public health authorities. This was felt to be a consequence of being incapable of controlling the risk of HIV transmission via blood transfusion $(\mathrm{n}=21)$. They felt that the HIV contaminated blood affair was seen by French society as a failure of the French Public Health system and that the public authorities should not remain inactive in the face of this distrust. Those interviewed thus considered the precautionary principle to be one of the responses to re-establish confidence $(n=8)$. It was felt that the precautionary principle was imposed from 1992 onwards to enable decisionmakers to take decisions immediately, without the need to wait for the results of scientific research. Such a decision, at the same time, enhanced the analysis of the potential risk Indeed, the interviewees indicated that French decision-makers were reproached during the HIV contaminated blood trial for their long delay in decision-making $(n=7)$.

A method for managing the potential risks associated with blood transfusion : The interviewees felt that for the field of blood transfusion, the precautionary principle had been imposed as a means of managing the associated risks, particularly those relating to possible prion $(\mathrm{vCJD})$ transmission $(\mathrm{n}=20)$. The use of the precautionary principle was also seen as a way by which the health authorities can reassure society and re-establish a climate of confidence. According to the interviewees, the institution of the precautionary principle would have major impact in four areas: scientific evaluation; the development of recommendations for decision-making; the economic acceptability of the imposition of certain measures; and the provision of information concerning the potential risks and the measures taken. Advantages and disadvantages of the application of the precautionary principle to blood transfusion were identified in the interviews for each of these areas. 


\section{Scientific evaluation}

The interviewees indicated that scientific evaluation was essential for decision-making $(\mathrm{n}=$ 14); that it should be independent and multidisciplinary $(\mathrm{n}=10)$; and that its objective should be to "rationalise uncertainty". In other words, scientific evaluation should aim to develop an epidemiological model based on the available data as well as a "worst-case scenario" $(n=4)$. It was felt that this model can then be used to construct knowledge concerning a potential risk (n =3). Such rationalisation requires a scientific method which should lead to the intensification of research to support the available knowledge in the affected domain $(n=11)$. Some interviewees $(n=6)$ (prescribers in particular) had doubts about the notion of "the rationalisation of uncertainty" because the latter is based on a worst-case scenario, which depends on the imagination of those constructing the model. Furthermore, it was felt that a theoretical risk model may be used for various strategic ends or to wrongly consider proven risk, when in fact it is no more than a hypothesis $(n=5)$. It was felt that such issues could lead to the irrational inflation of the perceived worst possible outcome, feeding fear $(n=5)$. Finally, there was also the question as to whether scientific evaluation focuses too heavily on epidemiological studies, to the detriment of economic and sociological considerations $(n=7)$.

\section{Participation of interested parties in the decision-making process}

The interviewees reported an evolution in the process used to develop recommendations for decision-making $(\mathrm{n}=17)$. In February 2000, a multidisciplinary group of experts drew up recommendations for the Minister of Health concerning decision-making relating to implementing precautionary principle measures with respect to potential transfusion transmission risks. Unfortunately, this group included none of the interested parties, such as patients' representative associations, or blood donors. The decisions taken (particularly the failure to exclude blood donors who had been to Great Britain) were thus contested by patient 
associations, who demanded the right to participate in the process of recommendation development. This demand was heard because in November 2000, when these recommendations were revised, a number of patient associations were invited to express their views. The exchanges and negotiations between the various parties led to more profound deliberations which resulted in a collective set of recommendations. The decisions made by public authorities on the basis of these revised recommendations were accepted by all parties. The opinions of the patients balanced those of the experts, thus widening the social debate. The interviewees stressed the importance of full participation and transparency for the reestablishment of patients' confidence in experts, transfusion institutions, and public authorities. Such confidence contributes to the acceptance of risk $(n=9)$.

The interviewees involved in the development of the final recommendations identified several problems. Firstly, some $(n=5)$ felt that the urgency with which decisions have to be made does not favour calm reflection and extensive participation. Secondly, some $(\mathrm{n}=3)$ raised the question of the legitimacy of the claims of certain peer pressure groups. Finally, some $(n=7)$ stressed the disadvantage of focusing on a potential risk rather than adopting a global approach which could result in the underestimation of other real risks, such as the interruption in the blood supply, a problem raised particularly by prescribers.

\section{The economic acceptability of some precautionary measures}

In Transfusion Medicine, the conflict between safety and economics raises ethical questions. Two trends were identified. For some $(\mathrm{n}=16)$ interviewees (prescribers and patients' representatives in particular), the precautionary principle should be applied as long as blood transfusion together with its potential risks is necessary to maximise safety, regardless of the cost involved $(n=4)$. Others $(n=13)$ believed that the decision should always take the cost/benefit ratio into account and should be accompanied by detailed information concerning 
the risk. The interviewees also felt that the public should be informed about the possibility of reversing precautionary measures based on the results of scientific research, to prevent the maintenance of useless and/or costly measures, simply for reassurance purposes $(n=5)$.

\section{Communicating Available Information}

For some interviewees $(\mathrm{n}=11)$, progress in knowledge about the risk of transfusiontransmitted prion disease and knowledge about the available preventive measures were felt to be significant. Some of the interviewees stressed the importance of providing new information and communicating this information to the general public $(n=6)$. They felt that new communication technologies could contribute to transparency and to the establishment of systems for teaching people about risks, making it possible for citizens to advance beyond their beliefs and their emotions $(n=3)$.

The demand for zero risk and the legal insecurity of the decision-maker: It was felt by some $(n=14)$ respondents that the sometimes incantatory use of the precautionary principle by public authorities lends credence to society's demands for zero risk in transfusion. By wanting to reassure the public, but at the same time focusing attention on possible risks, public authorities have created a source of fear that has led to this additional demand for safety. Some interviewees felt that this demand for maximal safety tended towards a demand for zero risk with some of these fears originating from the HIV contaminated blood affair.

According to those interviewed, public and private decision-makers have been destabilised in the long-term by this affair and its legal consequences, such as the condemnation of the French state for its public health deficiencies, and for not having taken the necessary measures early enough $(n=17)$. Faced with the necessity for action, it was felt that the public is now demanding maximal safety, particularly with respect to the risk of prion (vCJD) 
transmission by transfusion. Decision-makers therefore fear that they will be held legally responsible for not taking sufficient precautions particularly following verification of the hypothesis of a transfusion-associated vCJD risk.

Those interviewed did not know whether the precautionary principle would lessen the legal insecurity of the decision-maker because it was neither defined nor formalised when applied to blood transfusion. For them, the decision maker still remains at the mercy of a judge and was likely therefore to try to protect himself as much as possible. Furthermore, they wondered whether the precautionary principle is being used primarily to protect the decisionmaker rather than the affected patient. Some $(n=6)$ interviewees deplored this situation, but indicated that they felt powerless to change the situation. Furthermore, some respondents $(\mathrm{n}=$ 4) felt that the legal insecurity of the decision-makers was worsened by the obligation to obtain results and also by the undue delay in setting up a compensation scheme for those patients affected by certain therapeutic risks. 


\section{DISCUSSION}

The interpretations of the precautionary principle by a sample of individuals involved in Transfusion Medicine provides important information concerning the relevant historical basis, social significance, means of application, and consequences of the implementation of the precautionary principle. Some responses were commonly reported whereas others were less frequently enunciated. In spite of their scarcity, the latter were also taken into account because of the nature of the expressed perception or by whom they were expressed. These inclusions helped us to analyse whether the precautionary principle is relevant and whether it provides legitimate elements useful in risk management.

From the results obtained, the precautionary principle was perceived as originating from a founding event and as carrying both negative and positive elements. In France, the HIV/HCV contaminated blood affair was recognized as the founding event which established the use of the precautionary principle in Transfusion Medicine. Indeed, the impact of this affair was such that it may have led to the "world risk society" described by Beck (6). Considered a "scandal typical of modernity" (7), it led to a loss of confidence in public health by society as a whole. It deeply impacted French society and led to its social, legal and conceptual disruption. This was followed by profound changes in the perception and acceptability of proven and potential risks associated with transfusion (8). Risk was no longer acceptable, leading to a strong demand for maximal transfusion safety, the clear identification of responsibilities, the participation of patients' associations in decision making, the need for transparency, as well as public information. The previous system used for risk management was felt to have reached its limit of acceptability (9).

The different perceptions of the precautionary principle as applied to Transfusion Medicine today reveal that the precautionary principle is perceived primarily by professionals as a political way of action on the one hand, and as belonging to risk management in 
circumstances of scientific uncertainty on the other hand. However, it was felt that the precautionary principle leads to confusion because it is not clearly defined and thus tends to be misleading. This principle was not defined during its initial application to the field of Transfusion Medicine, contrarely to what was realized later for the law of February 1995 relating to the need for the protection of the environment. In particular, the Conseil d'Etat (10) gave a radical interpretation of the precautionary principle, which was used as the basis for the doctrine of maximal transfusion safety. The political or legal nature $(11,12)$ of the precautionary principle also remains unclear because it has never been defined properly. In our view, this is a major element that explains that too much room was left for interpretation, as discussed by the interviewees. This could explain the confusion between precaution and prevention, unknown risks and real risks. Precaution aims at managing potential risks while prevention aims at fighting real risks, even when those are rare. Our assumption is that this confusion will lead to the idea that it is necessary to be guaranteed about any risk and to apply the precautionary principle to all risks, proven or potential; thus leading to a refusal of acceptance of any risk. Whereas prevention aims at managing residual risks, the precautionary principle would push to seek risk zero. A slip of prevention towards precaution could constitute a non-acceptance of any risk, a position that could block some elements of medical progress, because a risk is always present. It is thus necessary that Transfusion Medicine professionals be very clear about interventions based on the precautionary principle, as it appears essential that, in order not to paralyse the health system, precaution should be considered in its right context.

The precautionary principle is also confusing because it forces society to think that it is possible to make decisions in the absence of definitive knowledge $(13,14)$. The application of the precautionary principle thus suggested to some interviewees that scientific uncertainty can be reduced, thereby preventing the transformation of a danger into a risk. It also acts as 
an amplifier of risk for society that focuses undue attention on the potential risks of transfusion whilst ignoring other (non-transfusion) risks prevalent in society.

Finally, the interpretations of some of those interviewed in this study show that the precautionary principle is seen as protecting the decision-maker rather than the patient. This key area of confusion results from a fear of being held responsible for deficient use of the precautionary principle in a very sensitive area of activity. Whereas the term "attitude of precaution" used initially (1) called to mind a particular state of mind and prudence, the term "precautionary principle" contains the obligation, laid down by the Conseil d'Etat to act, or not to act, according to the methods reputed to have no damaging effects (4). This could mean that the precautionary principle has the potential to transform risk taking into inaction even when a risk is minimal.

In the field of Transfusion Medicine, the legal situation of the decision-maker is also unclear, due to the conflict between society's demand for zero risk and the use of a treatment that is essential to save lives, but which carries certain risks. This legal insecurity, worsened by the tendency towards legal pursuits in medicine (15) can lead decision-makers to try to protect themselves against litigation. In the face of scientific uncertainty, a hypothetical risk that could be verified later and lead to demands for damages might cause decision-makers to err on the side of caution in an attempt to avoid being held legally responsible for not having taken appropriate measures at a given time. This can lead to an overestimation of a potential risk and the implementation of measures that are in some cases completely disproportionate to that risk, in order to protect themselves. Such fears relate to the possibility of being held responsible in cases of underestimation of risk, rather than of overestimation, which may have negative consequences, particularly for the available supply of labile blood products and the effective economic management of the transfusion system. 
With the use of the precautionary principle, a major issue is the absence of objective elements to enable the evaluation of the relevance of the policy decisions proposed. Furthermore, independent of a cost-benefit analysis, the economic dimension of the precautionary principle raises two fundamental ethical questions. First, in a society where the resources are limited and where there are important unsatisfied priorities in public health (ie treatment of cancer, how to deal with the handicapped, and the high risk of cardiovascular diseases), it is important to address the question as to whether it is worth investing resources to deal with hypothetical risks in situations where proven risks are not sufficiently resourced. Second, even if the financing of precaution is to be retained, the height of the financing should be balanced to that of the available research. Indeed, a balance should be sought between the cost of controls and of medical safety measures on one hand and the costs of financing research leading to a better understanding of the various risks on the other.

Finally, those questioned felt that the precautionary principle contained positive elements on collective thinking concerning risk management resulting in: a) systems of surveillance, vigilance and alert; b) procedures for evaluating potential risks; c) decision-making processes open to all interested parties; d) follow-up of measures; e) processes for informing professionals and the public; and f) compensation processes for victims. These latter elements may confer on the precautionary principle a dimension essential for rational action $(9,16-19)$. The most important part of such developments is the participation of all interested parties in policy decision-making. This is an essential part of the method for managing potential risks $(19,20)$ because it responds to social demands, places decision-makers in a more secure position, and renders a risk more acceptable. Social demands, which were very evident in the opinions expressed, are characteristic of the "risk society" (6). The "risk society" demands equality in the face of risk and refuses to be dependent on the scientific, medical and political elite, which is seen as manipulating the risks without involving, or necessarily informing, 
those who are exposed to them. Decisions based on recommendations derived from a collective development process thus make subsequent legal action difficult, if not impossible. A new social contract is thus established, based on agreement as to what is acceptable and what is not and on the conditions of acceptability. This acceptability will follow redefinition of the sharing of responsibility between the state and its citizens. Dialogue between science and society is also required (9). In the "risk society" (6), wide spread participation in decision-making is a means of ensuring confidence between the citizen and society's institutions.

Such participation appears in the compensation scheme laid down in the French law of March, 2002, concerning patients' rights. This issue is particularly sensitive in the field of Transfusion Medicine because, in the HIV contaminated blood affair, one of the "French exceptions" was the initial refusal to compensate victims (21).

It is essential that healthcare professionals and the public are kept informed as these concepts evolve, as such communication contributes to transparency and to inspiring confidence. The information provided must deal with both the risk and the uncertainty. Uncertainty is a key, topical issue that must be given a higher profile to combat the utopic notion of zero risk (22). 


\section{REFERENCES}

1. Assemblée Nationale: Speech of Bernard Kouchner, Minister of Health and Humanitarian Action on the occasion of presentation of the proposed law concerning the donation and therapeutic use of human blood and the organisation of blood transfusion. November $26^{\text {th }}, 1992$

2. Conseil d'Etat: Directive of April 9th 1993 (9 avril. - Assemblée.- 138653 - M.D.. Mme Mitjavile, rapp.; M. Legal, c. du g. ; Me Blanc, SCP Rouvière, Boutet, $a v$.). Recueil Lebon, 1993

3. Tabuteau D: Sécurité sanitaire et agences, le renouveau de la santé publique. Etudes et Documents - Conseil d'Etat 49:473-487, 1998

4. Conseil d'Etat: Rapport annuel 1998. Jurisprudence et avis de 1997. Réflexion sur le droit de la santé. Etudes et documents n 49. Paris, La documentation Française, 1998 5. Hergon $\mathrm{E}$ : Le principe de précaution appliqué à la transfusion sanguine. Thèse de Doctorat, Ethique Médicale et Biologique, Université Paris 5, 2002

6. Beck U: World Risk Society. Cambridge, Polity Press; 1999

7. Hermitte $\mathrm{M}$ A: Le principe de précaution à la lumière du drame de la transfusion sanguine en France, in Godard O (sous la direction): Le principe de précaution dans la conduite des affaires humaines. Paris, Editions de la Maison des sciences de l'homme et INRA, 1997, pp 179-198

8. Dab W: Santé publique, des crises aux ruptures, in Lagadec P: Ruptures créatrices, Paris, Editions d'Organisation, 2000, pp 313-333

9. Auberson-Huang L: The dialogue between precaution and risk. Nat Biotechnol 20:1076-1078, 2002 
10. Conseil d'Etat: Arrêté du 9 avril 1993 (9 avril. - Assemblée.- 138653 - M.D.. - Mme Mitjavile, rapp. ; M. Legal, c. du g. ; Me Blanc, SCP Rouvière, Boutet, $a v$.). Recueil Lebon :110-126,1993

11. Lascoumes $P$ : La précaution comme anticipation des risques résiduels et hybridation de la responsabilité. L’Année sociologique 2:359-382, 1996

12. Lascoumes $P$ : La précaution, un nouveau standard de jugement. Esprit 11:129-140, 1997

13. Setbon M: Le principe de précaution en questions. Revue des Affaires Sociales 34:201-207, 1997

14. Moutel G, Hervé C: Les risques d'une application aveugle du principe de précaution en médecine. La Presse Médicale 3:125-128, 2001

15. Burgelin JF: «N'assistons nous pas à une judiciarisation de la médecine ? ». 2003, Available at : www.inserm. fr/ethique

16. Foster KR, Vecchiaa $P$, Repacholi M: Science and precautionary principle. Science 288:979-981, 2000

17. Klinke A, Renn O: A new approach to risk evaluation and management : risk-based, precaution-based, and discourse-based strategies. Risk Analysis 22:1071-1094, 2002

18. Raffensperger $C$, Barett $K$ : In defense of the precautionary principle. Nat Biotechnol. $19: 811-812,2001$

19. Goklany IM: From precautionary principle to risk-risk analysis. Nat Biotechnol. $20: 1075,2002$

20. Viney G: Le principe de précaution est-il une règle de droit ? Les Cahiers du C.C.N.E. 24: $30-34,2000$

21. Kriegel B : La responsabilité politique et pénale dans l'affaire du sang contaminé. Journal international de bioéthique 2:59-71, 2001 
22. Wilson K, Wilson M, Hébert PC, Graham I : The Application of the Precautionary

Principle to the Blood System: The Canadian Blood System's vCJD Donor Deferral

Policy. Transfusion Medicine Reviews 17:89-94, 2003 